\title{
Investigating the impact of Computer Supported Collaborative Learning (CSCL) to help improve reading comprehension in low performing urban elementary schools
}

\author{
Natalia Vega ${ }^{1} \cdot$ James Stanfield $^{1}$ (D) $\cdot$ Sugata Mitra ${ }^{1}$
}

Received: 12 July 2019 / Accepted: 20 September 2019 / Published online: 1 November 2019

(C) The Author(s) 2019

\begin{abstract}
In the United States, literacy rates vary between socio-economic groups, and this reading gap is also a common feature in the education systems of OECD member states. To help address this reading gap previous research has identified a number of teaching strategies that have a positive impact on student learning outcomes, including the use of peer collaboration and complex texts. However, the contribution of Computer Supported Collaborative Learning to help address the reading gap for students attending low performing urban elementary schools has, to date, received much less attention and little is known about the ability of young students with access to the Internet to read complex texts in groups and how this impacts on individual reading comprehension scores. This study therefore examines the impact of combining the use of complex texts, collaborative learning and access to the internet on the reading comprehension scores of 58 fourth-grade students (ages 10-11). The students met once a week for an hour over six consecutive weeks and read under the following three conditions: eighth grade level texts independently, eighth grade level texts in groups with internet access and fourth grade level texts in groups with internet access. Our findings demonstrate that groups of young students with access to the internet are capable of reading complex texts with minimal teacher intervention. We also believe that this approach has the potential to help students develop both their offline and online reading comprehension skills.
\end{abstract}

Keywords Computer Supported Collaborative Learning $\cdot$ Reading comprehension

James Stanfield

james.stanfield@ncl.ac.uk

1 School of Education, Communications and Language Sciences, Newcastle University, Newcastle, UK 


\section{Introduction}

In 1964 a Commission on Equality of Opportunity was established in the United States to help address the growing concerns about the lack of equal educational opportunities in public schools. The findings, published in the Coleman Report (1966), identified a reading gap between children from different socioeconomic backgrounds and this gap continues to persist. The most recent data from the National Assessment of Educational Process (2017), shows that only $21 \%$ of children who are eligible for the National School Lunch Program (NSP) were scoring at or above proficient in reading and $64 \%$ are scoring below the basic level. This is compared to $51 \%$ of children who are not eligible for the NSP scoring at or above proficient in reading and only $18 \%$ scoring below the basic level (McFarland et al. 2017). There is also evidence to suggest that this gap is now widening (Reardon 2011). This reading gap is also replicated, to a certain extent, across all OECD member states (OECD 2010a) and according to Mullis et al. (2017), this is also reflected in the data from the latest Progress in International Reading Literacy Study (2016).

Recognising the existence of this reading gap and its link to declining levels of social mobility in the United States (Hungerford 2011), has also helped to reinforce the important role that schools can play in helping to improve social mobility by reducing the reading gap. For example, some countries have narrowed this reading gap by introducing policies that target low performing and socio-economically disadvantaged students and schools, including the introduction of specialised curriculum and additional instructional resources (OECD 2010b). In the United States the National Reading Panel (NRP) previously identified sixteen distinct categories of instruction to help improve reading comprehension and the following seven were recognised as being effective and the most promising for classroom instruction: comprehension monitoring, cooperative learning, graphical representation, story structure, question and answering generation, summarization and multiple-strategy teaching (NRP 2000). However, this research was carried out before the Internet became more widely available in classrooms via mobile devices using Wi-Fi technology. These developments occurred post 2010 and were accelerated following the launch of the ConnectED Initiative by President Obama in 2013. The purpose of this study therefore was to investigate the impact of combining the use of collaborative learning, complex texts and access to the Internet on the reading comprehension scores of 58 fourth-grade students (ages 10-11) and to consider what role this approach might play in helping to reduce the reading gap in low performing urban elementary schools.

\subsection{Reading comprehension and collaborative learning}

One possible solution to this reading gap is peer collaboration (PColl) for reading practices which has typically involved a more capable reader supporting a reader in need, always mediated by adult instruction and supervision (Stevens et al. 1991; RojasDrummond et al. 2014). Several studies have since highlighted the benefits of peer collaboration for children's early literacy development (Howe et al. 2016; Howe et al. 2015; Pérez-Granados and Callanan 1997; Strauss and Ziv 2012). For example, with Peer Assisted Learning Strategies (PALS), students are grouped in pairs based upon their individual needs and the less able student is supported and encouraged to acquire 
new reading skills (Fuchs et al. 2000). Research has confirmed that this approach can help struggling readers to improve a range of early literacy skills (Lemons et al. 2014). Furthermore, Stevens et al. (1991) found that when students were provided with direct teaching on reading strategies and then given the opportunity to practice these strategies in collaborative groups, students scored higher in reading comprehension tests than when direct instruction was removed. Similarly, Morgan et al. (2000) showed that while reading in dyads and after adult instruction in how to conduct dyad interaction for reading, struggling readers benefited from practice with a more capable peer when text complexity control measures were taken into account.

\subsection{Reading comprehension and text complexity}

The Common Core State Standards (CCSS) in the United States provide clear and consistent learning goals which demonstrate what students are expected to learn at each grade level. While the CCSS do not dictate how the standards should be taught or what kind of learning materials should be used, leveled texts - books that give every learner access to content at an appropriate level of challenge - continue to play a dominant role (Amendum et al. 2018). Adapting text to reader's abilities therefore remains one of the most prominent compensatory measures in reading instruction. However, the concept remains contested (Kuhn and Stahl 2003, Fisher and Frey 2012) and it has been suggested that its overuse has contributed to the reading gap in America as it disregards new complex reading demands, which are difficult to address in these highly controlled environments (NGA Center and CCSSO 2010). The idea of raising the complexity level in order to challenge students is supported by a number of studies. For example, in a meta-analysis of studies in fluency instruction that used reading materials at or above the participants' instructional level, Kuhn \& Stahl concluded that more difficult materials would lead to greater gains in achievement (Kuhn and Stahl 2003). Shanahan, Fisher, \& Frey have also concluded that it will be impossible to build robust reading skills without reading challenging text (Shanahan et al. 2012). In the research on peer collaboration carried out by Morgan et al. (2000), they also found that when texts were two grade levels above the readers' abilities, reading scores in standardised tests improved more than when texts were much higher or at the readers' level. More recent research has also found that the assisted readers reading texts two grade levels above their instructional levels showed the most robust gains in oral reading fluency and comprehension (Brown et al. 2018). These research findings are also reinforced by the wider research comparing collaborative and individual learning which has found that learning efficiency is greater in group learning than individual learning when the problem-solving tasks are relatively complex (e.g., Kirschner et al. 2009; Laughlin et al. 2002; Laughlin et al. 2006).

Taking part in this type of group activity may therefore help to improve the performance of participating individuals, although this may not be the case with relatively simple tasks. In short, group members tend to learn in a more efficient way than individual learners when faced with high-complexity tasks, while individual learning tends to be more efficient for low-complexity tasks (Kirschner et al. 2011). This existing research and the call for additional research to be carried out to examine the potential use of more complex texts as a method for increasing reading achievement (Morgan et al. 2000, Shanahan 2005, Shanahan et al. 2012 and Stahl 2012), reinforces the need for additional research in this area. 


\subsection{Computer Supported Collaborative Learning (CSCL)}

Computer-Supported Collaborative Learning (CSCL) is a pedagogical approach which emerged during the 1990s to explore the potential of combining computer support and collaborative learning to enhance the learning experience (Stahl et al. 2006). In response to the growth of software to support learners as isolated individuals, CSCL is seen as a dynamic, interdisciplinary, and international field of research which is focused on studying how people learn collaboratively in small groups and in learning communities with the help of technology (Resta and Laferrière 2007). In this context learning takes place via social interaction and involves the sharing and construction of knowledge, with technology being used either as the primary means of communication or simply as a common resource. CSCL therefore embraces a more situated view of learning (Stahl et al. 2006) and is motivated by social constructivist (Lave and Wenger 1991) and dialogical theories of learning where collaboration is seen as a process of shared meaning construction and learning is the act of bringing divergent meanings into contact with each other. CSCL also draws on learning theories which focus on the social aspect of learning and building knowledge as a group, including: distributed cognition, problem-based learning, group cognition and cognitive apprenticeship (Resta and Laferrière 2007). A meta analysis carried out by Lou, Abrami and d'Apollonia (2001), found that CSCL produced substantially better group products than individual products and students also gained more individual knowledge than students learning with computer technology by themselves. The literature also suggests that the nature and size of the effect will depend on a number of learner characteristics. For example, Lou, Abrami and d'Apollonia (2001) found that learning was significantly enhanced when students had experience of working in groups; when cooperative learning strategies were used; when the group size was small and finally when students were either relatively low or relatively high in ability.

Research on the use of CSCL to help improve reading comprehension is limited and to date it has focused on the use of a number of software programmes (Yang et al. 2011). However, in language learning, CSCL has been found to increase student confidence, encourage active learning and reduce learner anxiety (Lan et al. 2007). Research by Dooly (2007) has also found that that during computer supported collaborative language learning, students tend to develop an increased awareness of different aspects of the new language and they also pay increased attention to their own language learning process. While the research referred to above has involved participants collaborating online using a variety of different software applications, in the research reported in this paper, the participants were collaborating face to face within a classroom environment, using the Internet as a research tool.

\subsection{New literacies theory}

The potential of using the Internet as a research tool in the classroom is therefore a relatively recent development and with reference to the challenge of improving reading comprehension, it introduces a fascinating new dynamic. The New Literacies theory (Coiro et al. 2008; Leu et al. 2004) recognizes that the nature of literacy is now continuously changing as new technologies emerge and this has resulted in the growth and development of new skills. The new literacies perspective of online research and 
comprehension (Leu et al. 2004; Leu et al. 2014) frames online reading comprehension as a self-directed process of constructing texts and knowledge while engaging in a number of online practices including: reading to define important questions; reading to locate relevant information; reading to critically evaluate information for accuracy, reliability, and stance; reading to synthesise information across multiple sources; and reading and writing to communicate their findings to others (Coiro et al. 2008). These complex tasks require the use of higher order thinking skills such as problem solving and critical thinking (Leu et al. 2014) and at times the exercise of digital wisdom (Coiro 2014) to critically evaluate the trustworthiness of what is being read in order to ensure proper use of the information. This fascinating new dynamic therefore relates to the fact that the technology that has been selected to help improve reading comprehension is at the same time also enabling a new form of reading comprehension to emerge in a completely new context.

To conclude, there is some evidence to support the use of collaborative learning and the use of complex texts to help improve reading comprehension in a traditional classroom environment. There is also some research to support the use of CSCL to help improve reading comprehension, however this research to date has not focused on the use of the Internet as a research tool. This investigation will therefore help to shed light on the potential impact of using CSCL to help improve reading comprehension, and it will also raise questions about the potential of using this approach to help improve both offline and online reading comprehension in low performing urban elementary schools.

\subsection{The present study}

Our study aims to explore if the combined use of collaborative learning and access to the Internet can help children comprehend complex texts with minimal teacher intervention. We therefore investigated a) was there was a measurable difference in the reading performance of fourth-grade students when reading eighth-grade level texts in collaborative groups with Internet access as opposed to reading individually without access to the Internet and b) was there was a measurable difference in the reading performance of fourth-grade students when reading fourth versus eighth-grade texts in collaborative groups with access to the Internet. This quantitative study answered both research questions through measuring participant's responses to reading comprehension questions after reading offline texts. The study was hypothesis driven and statistical analysis was used to evaluate the following two null hypotheses:

- $\mathrm{H}_{1}$. Fourth-grade students of New York City public schools will not display statistically significant difference in comprehension levels when reading eighthgrade level texts individually in comparison to group reading with Internet access for research support as measured by the scores obtained on text comprehension questions; and

- $\mathrm{H}_{2}$. Fourth-grade students of New York City public schools will not display statistically significant difference in comprehension levels when reading in groups with Internet access for research support of fourth-grade level texts in comparison to reading eighth-grade level texts, as measured by the scores obtained on text comprehension questions. 


\subsection{Participants and procedure}

The selection process resulted in a sample of 57 fourth-grade students (ages 10-11) from two elementary public schools in New York City. School 1 had 36 students and School 2 had 21, and all 57 participated of all research conditions. The two schools were geographically close and they shared similar characteristics (i.e. socio-economic status, academic achievement and needs). Both schools had over $90 \%$ student living in poverty as defined by the public schools standards and both schools had the majority of fourth-graders failing the English Language Arts State Assessment (ELASA). In 2014 the pass rate in School 1 was 19.8\% and only 9.8\% in School 2. This is compared to the city-wide pass rate of $31.1 \%$ in the same year (CC YEAR 2014). Both schools also followed similar reading curriculums aligned to the Common Core Learning Standards.

Reading activities were conducted in existing classrooms outside of normal school hours and each classroom was equipped with laptops and Internet connection (one device per four students), booklets and pencils. The Department of Education of New York City provided Internet connection, which was properly protected to prevent access to material inappropriate to the students' age. All activities were facilitated by a researcher who was the gatekeeper and data collector, after obtaining proper documentation and ethical approval to conduct research in these two settings. The researcher did not interact with students during the reading and writing process and the students received no instruction in how to effectively collaborate and converse in group reading situations.

Fourth grade students read under the following three conditions:

- Eighth-grade level offline texts independently

- Eighth-grade level offline texts in groups with Internet access as a supporting tool

- Fourth-grade level offline texts in groups with Internet access as a supporting tool

Each session included approximately twenty participants and they met once a week for an hour, for six consecutive weeks. During each session, participants read three texts representing each research condition for twenty minutes each and then answered four comprehension questions per text. For group reading, groups were selfselected with a maximum number of four students. All students were given the same directions and differentiated treatment was avoided to ensure students perceived each other as equal collaborators. At the end of each session, all of the materials were collected, de-identified and coded to protect participants' identity. After deidentification, the answers were scored and entered for analysis into the IBM Statistical Package for the Social Sciences. The data set was scored using a modified version of the New York State English Language Test Blue Print Rubric and data was quantitised using a zero to two-point scale for each category. Missing information was given a score of 999. This data set was scored using a modified version of the New York State English Language Test Blue Print Rubric and data was quantitised using a zero to two-point scale for each category. Missing information was given a score of 999. A one-way ANOVA was conducted to test null hypotheses $\mathrm{H}_{1}$ and $\mathrm{H}_{2}$, to compare multiple means to see whether they were similar or statistically significant different. 


\section{Results}

Students in the fourth-grade in New York City obtained better scores when reading eighth-grade texts in groups with access to the Internet as opposed to reading individually without access to the Internet, in all obtained measures. However, when comparing group reading of complex texts to at-grade-level texts, neither condition was favoured. Results were analysed using descriptive statistics to identify mean differences; then, homogeneity of variance was conducted to test if all groups had the same or similar variance associated with each ANOVA, which led to determine if a statistically significant difference existed between the independent variables mentioned above. Finally, a post-hoc analysis was used to show the means for which statistical variance was detected.

\subsection{Individual vs group reading with internet access of complex and at-grade-level texts}

A one-way ANOVA was used to determine mean difference in the scores obtained during reading individually as opposed to reading in groups (see Table 1). Statistical significance at the .001 alpha level was indicated in all cases, showing that all these outcome measures significantly differ on the basis of group membership, which were categorized as 8th Grade, Individually; 8th Grade, Groups; and 4th Grade, Groups. In this way for session $1 \mathrm{~F}(\mathrm{df} 117)=$ 44.034; session $2 \mathrm{~F}(d f 118)=23.838$; session $3 \mathrm{~F}(d f 143)=64.792$; session $4 \mathrm{~F}(d f 130)=71.158$; session $5 \mathrm{~F}(d f 130)=74.855$; session $6 \mathrm{~F}(d f 105)=$ 54.044 ; 8th Grade, Individually $\mathrm{F}(d f \mathrm{172})=100.762$. However, it is noted that the ANOVA only revealed mean difference between and within groups, and that a post-hoc analysis was needed to uncover the source of differences. This posthoc analysis showed that in all six sessions reading individually was found to have significantly lower scores as compared to reading in groups.

\subsection{Group reading of complex vs at-grade-level texts}

The one-way ANOVA showed that reading in groups did not favour either condition: group reading of eighth-grade texts over group reading of at-grade-level texts. Then, a post-hoc analysis indicated that in three out of six occasions, the mean for reading complex texts in groups was higher, yet not statistically significant different from reading at-grade-level texts. Similarly, the mean for 4th Grade, groups was found to be higher in three out of six occasions but only statistical significant difference was determined for session 3. That is, Post-hoc comparison using Games and Howell (GH) test indicated that the mean score for reading eighth-grade text in comparison to fourthgrade level texts did not favour either condition as follows: session $1(M=.658$, $S E=.345, p=.149)$ showed no statistical significant difference; session $3(M=1.245$, $S E=.248, p=.00)$ was statistically significant; session $4(M=.668, S E=.323$, $p=.108)$ was not statistically significant; session $5(M=1.052, S E=.387, p=.024)$ was not statistically significant; session $6(M=.038, S E=.617, p=.998)$ was not statistically significant. For session 2 Tukey HSD test shows no statistically significance: session $2(M=.242, S E=.363, p=.784)$. 
Table 1 One-Way ANOVA for Reading Individually and in Groups

\begin{tabular}{|c|c|c|c|c|c|}
\hline Measure & Sum of Squares & $d f$ & Mean Square & $F$ & $p$ \\
\hline \multicolumn{6}{|l|}{ Session 1} \\
\hline Between Groups & 105.603 & 2 & 52.802 & \multirow[t]{2}{*}{44.034} & \multirow[t]{2}{*}{.000} \\
\hline Within Groups & 137.897 & 115 & 1.199 & & \\
\hline Total & 243.500 & 117 & & & \\
\hline \multicolumn{6}{|l|}{ Session 2} \\
\hline Between Groups & 120.673 & 2 & 60.337 & \multirow[t]{2}{*}{23.838} & \multirow[t]{2}{*}{.000} \\
\hline Within Groups & 293.612 & 116 & 2.531 & & \\
\hline Total & 414.286 & 118 & & & \\
\hline \multicolumn{6}{|l|}{ Session 3} \\
\hline Between Groups & 144.297 & 2 & 72.149 & \multirow[t]{2}{*}{64.792} & \multirow[t]{2}{*}{.000} \\
\hline Within Groups & 157.008 & 141 & 1.114 & & \\
\hline Total & 301.306 & 143 & & & \\
\hline \multicolumn{6}{|l|}{ Session 4} \\
\hline Between Groups & 196.671 & 2 & 98.336 & \multirow[t]{2}{*}{71.158} & \multirow[t]{2}{*}{.000} \\
\hline Within Groups & 176.886 & 128 & 1.382 & & \\
\hline Total & 373.557 & 130 & & & \\
\hline \multicolumn{6}{|l|}{ Session 5} \\
\hline Between Groups & 280.647 & 2 & 140.324 & \multirow[t]{2}{*}{74.855} & \multirow[t]{2}{*}{.000} \\
\hline Within Groups & 239.948 & 128 & 1.875 & & \\
\hline Total & 520.595 & 130 & & & \\
\hline \multicolumn{6}{|l|}{ Session 6} \\
\hline Between Groups & 265.247 & 2 & 132.624 & \multirow[t]{2}{*}{54.044} & \multirow[t]{2}{*}{.000} \\
\hline Within Groups & 252.762 & 103 & 2.454 & & \\
\hline Total & 518.009 & 105 & & & \\
\hline \multicolumn{6}{|c|}{ 8th Grade, Individually } \\
\hline Between Groups & 3775.787 & 2 & 1887.894 & \multirow[t]{2}{*}{100.762} & \multirow[t]{2}{*}{.000} \\
\hline Within Groups & 3185.138 & 170 & 18.736 & & \\
\hline Total & 6960.925 & 172 & & & \\
\hline
\end{tabular}

The analysis of results allowed for the rejection of the null hypotheses for research question 1: fourth-graders of New York City public schools will not display statistically significant difference in comprehension levels when reading 8th-grade level texts individually in comparison to group reading with Internet access for research support. In addition, the results have favoured reading in groups in all measures participants obtained higher scores. In contrast, analysis of results did not allow for the rejection of the null hypotheses for research question 2: fourth-graders of New York City public schools will not display statistically significant difference in comprehension levels when reading in groups with Internet access for research support of fourth-grade level texts in comparison to reading eighth-grade level texts. Results indicated no statistical significant difference for either condition. 


\section{Discussion}

Overall, research conditions in this study (i.e. reading fourth and eighth-grade texts, individually and in groups) show that when reading in groups, participants do not necessarily require adult intervention, control of text complexity and peers as tutors. That is, traditional scaffolds were not used as supports, but participants' as collaborators enabled text comprehension. This absence of traditional scaffolds contributes to the body of knowledge related to reading in peer-mediated activities and it challenges the notion that young readers always require instruction in collaborative skills or additional reading strategies to successfully carry out collaborative reading enterprises for comprehension. Although limited by the data collected, the results suggest that the Internet - when used as a research tool - can act as a scaffold, supporting the solution of these complex texts, suggesting that participants' comprehension was enhanced by the combination of group work and the Internet, in the absence of instruction and control of text complexity.

\subsection{The use of scaffolds with CSCL}

These results bring into question different aspects of group work for reading in the areas of: use of traditional scaffolds to achieve reading comprehension, introduction of the internet as a research tool and group collaboration. Most common scaffolds found in the literature were text complexity, teacher intervention and peers as tutors. The use of text complexity, a central tool to the Common Core Standards of education in the United States (EngageNY.org 2012), did not show statistical significant differences between reading fourth and eighth-grade texts when students read in groups but statistical difference was found when reading eighth grade texts in groups as opposed to individually. This indicates that controlling for complexity when reading in groups may not be necessary, although it still affects individual reading. These findings also bring into question text complexity as essential to the instruction of reading and puts forward the need to broaden the spectrum of how reading is understood, that is, from the construction of text to a much larger activity called comprehension of the Internet. In this case, areas such as group work, integration of information from different resources and evaluation of information trustworthiness - to name a few - gain a central status in academic instruction, which can no longer be called reading instruction as it goes beyond the act of reading. Results also show that controlling for text complexity is unnecessary when fourthgraders read in groups with Internet access for support. Participants are statistically more successful when reading in groups as opposed to individually under both conditions, reading at-grade-level and above-grade level texts.

Another common scaffold in group work for reading is peers as tutor, which was avoided in this study. All students were given the same directions and differentiated treatment was avoided to ensure students perceived each other as equal collaborators. This brings attention to a shift in how students are perceived, that is, from a view of capable/less capable students and from skill knowledge/lack of skills to what each student can bring to a collaboration to ensure text comprehension. Then, it can be implied that each member of the group brought to the interaction a diversity of skills beyond reading- that made comprehension possible. 
These common scaffolds (i.e. text complexity, teacher instruction and peers as tutors) were embraced at a time when the Internet was not a tool in the classroom. Presently, in Internet enabled settings, these scaffolds may become less necessary as students' natural attitudes towards collaboration and all the tools found in the Internet allows comprehension to occur. Tools such as hyperlinks, videos, and images seemed to support comprehension of fourth and eighth-grade texts when students read in collaborative groups. This brings new possibilities for students and teachers: a new and expanded definition of reading, new approaches to reading individually and in groups, and most importantly the inevitable shift from offline reading to Internet comprehension. As for group work, it seems contra intuitive that neither condition (i.e. Reading fourth and eighth-grade texts in groups) was favoured. Since one text was easier to read than the other, it would be expected that students would score best in the easier text, and yet, in individual reading of eighth-grade texts, comprehension hardly emerged. This indicates that student collaboration was the driving force enabling comprehension that was higher than individual reading ability. Groups provided the individual with a better environment to comprehend text of diverse levels and also as a way for students to construct texts together.

\subsection{The changing role of the teacher}

Another unique feature of this study was that students engaged with reading comprehension tasks within a classroom environment but with minimal teacher intervention. In the study, the presence of adults was exclusively for providing safety and order and to assist students with technical difficulties they might have experienced with the computers. In other words, teachers did not interact with students during the reading and writing process. Teacher instruction in how to effectively collaborate and converse in group reading situations was also purposely avoided and the researcher only provided encouragement and safety where needed. Both research conditions (i.e. Reading fourth and eighth-grade level texts, individually and in groups) show that when reading in groups with access to the Internet, participants do not necessarily require adult intervention or support to help answer comprehension questions. Further research would be required to better understand the impact (either positive or negative) of increasing teacher intervention within this context. Previous research on the role of scaffolding in online CSCL environments has shown that getting the right balance between guidance and support to facilitate a variety of different learners within a group can be a complex and a delicate issue (Rienties et al. 2012).

It will be important to note however, that teachers did still play an important role in this study because all of the participants received reading instruction for at least four years of schooling prior to the study and they all had sufficient knowledge of reading to solve comprehension questions given at the end of a set text. Furthermore, it was the teacher who designed the group activity and it was also the teacher who provided an appropriate classroom environment to enable the activity to take place. The teacher therefore still played a significant role without engaging in any direct teaching. The role of the teacher changes to being more of a 'curator' who creates spaces in which knowledge can be created, explored and connected (Siemens 2005). Additional recent research also suggests that the notion of groups of students improving their levels of literacy themselves with minimal adult input, is not unique. Young siblings (including 
preschool-and school-age children) within the home environment, have been found to engage in spontaneous, naturalistic, and unstructured teaching of language and literacy concepts without parental involvement. While it is not recommended that parents forgo the teaching role entirely, they do suggest that parents should be aware that siblings will teach and learn from each other, especially if a wide variety of literacy materials are available. Within a connected classroom environment, access to a much wider variety of literacy materials has now become possible and so this may raise the prospect of more opportunities for spontaneous forms of language learning in the classroom in the future.

\section{Conclusions and limitations}

As noted earlier this fascinating new dynamic refers to the fact that the technology that has been selected to help improve reading comprehension is at the same time also enabling a new form of reading comprehension to emerge in a completely new context. While the majority of research into CSCL has focused on collaborative learning within online learning platforms or using particular software applications, there has been less interest in the use of the Internet as a source of information by groups of students collaborating within the traditional classroom environment. This is perhaps surprising when we take into account that the fact that the Internet has now evolved into a global system of interconnected computer networks which are linked by a variety of networking technologies, creating the largest information construct in human history. It not only has world-wide broadcasting capability, but it is also a mechanism for information dissemination, and a medium for collaboration and interaction without regard for geographic location. The Internet is therefore not simply a tool or a kind of technology that is being employed to help support collaborative learning. It is clearly much more than that, providing an entirely new context in which children learn resulting in the emergence of a new form of literacy. All of this is relevant because it is our contention that a modified version of the approach that we used in this research has the potential not only to improve traditional reading compression skills and reduce the reading gap but also to improve online reading compression and digital literacy skills more generally. In the US and other countries around the world, traditional literacy is still, to a large extent, taught separately from digital literacy and so this simple approach could be used to help start bridge the differences between the two.

The findings presented in this paper add to the existing body of research on the growing use of the Internet in the classroom as an information seeking tool to help children improve numerous skills including reading comprehension. To the best of our knowledge, this is the first investigation into reading comprehension in low performing urban elementary schools that has combined the use of complex texts, collaborative learning and the use of the Internet. A unique feature of our study was that reading comprehension emerged from within the group, but with minimal teacher intervention. This suggests that a broader perspective on the role of the teacher in literacy learning within a connected classroom is now required to take into account the development of digital literacy skills alongside traditional literacy skills.

This study also has a number of limitations which must be taken into account. First, the intervention was limited to six sessions of one hour and three texts per session. 
While there is no agreed definition of how long a sustained intervention needs to be within this field, Wanzek et al. (2010) excluded all interventions from a meta-analysis which lasted for less than fifteen sessions. Future research will therefore need to take this into account. Second, the findings of this study are limited to fourth-grade students attending two underperforming public schools in New York City. The findings can therefore only be generalized to this population. Third, CSCL has previously been characterized as consisting of the following three methodological traditions: experimental, descriptive and iterative design (Stahl et al. 2006). However, the form of experimental research which was used in this research does not help to shed any light on how the groups collaborated and what role the internet played in supporting or disrupting the learning process. Ideally, it would therefore be combined with descriptive case analyses which would examine the structure and intention of unique cases of interaction, a method more suited to the ethnomethodological tradition (Koschmann et al. 2006; Koschmann et al. 2003; Stahl et al. 2006).

Open Access This article is distributed under the terms of the Creative Commons Attribution 4.0 International License (http://creativecommons.org/licenses/by/4.0/), which permits unrestricted use, distribution, and reproduction in any medium, provided you give appropriate credit to the original author(s) and the source, provide a link to the Creative Commons license, and indicate if changes were made.

\section{References}

Amendum, S. J., Conradi, K., \& Hiebert, E. (2018). Does Text Complexity Matter in the Elementary Grades? A Research Synthesis of Text Difficulty and Elementary Students' Reading Fluency and Comprehension. Educational Psychology Review, 30(1), 121-151. https://doi.org/10.1007/s10648-017-9398-2.

Brown, L. T., Mohr, K., Wilcox, B. R., \& Barrett, T. S. (2018). The effects of dyad reading and text difficulty on third-graders' reading achievement. The Journal of Educational Research, 111(5), 541-553. https://doi.org/10.1080/00220671.2017.1310711.

Coiro, J., Knobel, M., Lankshear, C., \& Leu, D. J. (2008). Central issues in new literacies and new literacies research. In J. Coiro, M. Knobel, C. Lankshear, \& D. J. Leu (Eds.), The Handbook of Research on New Literacies (pp. 1-22). Mahwah: Erlbaum.

Coiro, J. (2014). Online reading comprehension: Challenges and opportunities. Texto Livre: Linguagem e Tecnologia, 7(2), 30-43.

Dooly, M. (2007). Joining forces: Promoting metalinguistic awareness through computer-supported collaborative learning. Language Awareness, 16(1), 57-74. https://doi.org/10.2167/la413.0.

EngageNY.org (2012). New York State P-12 Common Core Learning Standards. Retrieved from: http://www. engageny.org/resource/new-york-state-p-12-common-core-learning-standards

Fisher, D., \& Frey, N. (2012). Motivating Boys to Read: Inquiry, Modeling, and Choice Matter. Journal of Adolescent and Adult Literacy, 55(7), 587-596. https://doi.org/10.1002/JAAL.00070.

Fuchs, D., Fuchs, L. S., \& Burish, P. (2000). Peer-assisted learning strategies: An evidence-based practice to promote reading achievement. Learning Disabilities Research and Practice, 15(2), 85-91. https://doi. org/10.1207/SLDRP1502_4.

Howe, N., Della Porta, S., Recchia, H., Funamoto, A., \& Ross, H. (2015). This bird can't do it 'cause this bird doesn't swim in water: Sibling teaching during naturalistic home observations in early childhood. Journal of Cognition and Development, 16, 314-332. https://doi.org/10.1080/15248372.2013.848869.

Howe, N., Della Porta, S., \& Recchia, H. (2016). Because If You Don’t Put the Top on, It Will Spill: A Longitudinal Study of Sibling Teaching in Early Childhood. Developmental Psychology, 52(11), 18321184.

Hungerford, T. L. (2011). How income mobility affects income inequality: US evidence in the 1980s and the 1990s. Journal of Income Distribution., 16(2), 83-103.

Kirschner, F., Paas, F., \& Kirschner, P. A. (2009). Individual and group-based learning from complex cognitive tasks: Effects on retention and transfer efficiency. Computers in Human Behavior, 25, 306-314. https://doi.org/10.1016/j.chb.2008.12.008. 
Kirschner, F., Paas, F., \& Kirschner, P. A. (2011). Task complexity as a driver for collaborative learning efficiency: The collective working-memory effect. Applied Cognitive Psychology, 25, 615-624. https://doi.org/10.1002/acp.1730.

Koschmann, T., Stahl, G., \& Zemel, A. (2006). The video analyst's manifesto (or the implications of Garfinkel's policies for the development of a program of video analytic research within the learning sciences). In R. Goldman, R. Pea, B. Barron \& S.Derry (Eds.), Video research in the learning sciences. Retrieved from http://www.cis.drexel.edu/faculty/gerry/publications/journals/manifesto.pdf.

Koschmann, T., Zemel, A., Conlee-Stevens, M., Young, N., Robbs, J., \& Barnhart, A. (2003). Problematizing the problem: A single case analysis in a dPBL meeting. In B. Wasson, S. Ludvigsen \& U. Hoppe (Eds.), Designing for change in networked learning environments: Proceedings of the international conference on computer support for collaborative learning (CSCL '03) (pp. 37-46). Bergen, Norway: Kluwer Publishers.

Kuhn, M. R., \& Stahl, S. A. (2003). Fluency: A review of developmental and remedial practices. Journal of Educational Psychology., 95, 3-22. https://doi.org/10.1037/0022-0663.95.1.3.

Lan, Y. J., Sung, Y. T., \& Chang, K. E. (2007). A mobile-device-supported peer-assisted learning system for collaborative early EFL reading. Language Learning \& Technology, 11(3), 130-151.

Laughlin, P. R., Hatch, E. C., Silver, J. S., \& Boh, L. (2006). Groups perform better than the best individuals on letters-to-numbers problems: effects of group size. Journal of Personality and Social Psychology., 90(4), 644-651. https://doi.org/10.1177/1368430208090645.

Laughlin, P. R., Bonner, B. L., \& Miner, A. G. (2002). Groups perform better than the best individuals on Letters-to-Numbers problems, Organizational Behavior and Human Decision Processes. Elsevier, 88(2), 605-620. https://doi.org/10.1016/S0749-5978(02)00003-1.

Lave, J., \& Wenger, E. (1991). Situated Learning: Legitimate Peripheral Participation. Cambridge: Cambridge University Press.

Lemons, C. J., Kearns, D. M., \& Davidson, K. A. (2014). Data-Based Individualization in Reading: Intensifying Interventions for Students With Significant Reading Disabilities. Teaching Exceptional Children, 46(4), 20-29.

Leu, D.J., Kinzer, C.K., Coiro, J.L. and Cammack, D.W. (2004). Toward a theory of new literacies emerging from the Internet and other information and communication technologies, In Ruddell, Robert B., Ed.; Unrau, Norman J., Ed. Theoretical Models and Processes of Reading, 1570-1613.

Leu, D. J., Forzani, E., Rhoads, C., Maykel, C., Kennedy, C., \& Timbrell, N. (2014). The New Literacies of Online Research and Comprehension: Rethinking the Reading Achievement Gap. Reading Research Quarterly, 50(1), 37-59. https://doi.org/10.1002/rrq.85.

Lou, Y,. Abrami, P.C. \& d'Apollonia, S. (2001) Small Group and Individual Learning with Technology: A Meta-Analysis. Review of Educational Research, 71(3) 449-521. https://doi.org/10.3102 /00346543071003449.

Morgan, A., Wilcox, B., \& Eldredge, J. L. (2000). Effect of difficulty levels on second- grade delayed readers using dyad reading. The Journal of Educational Research, 94(2), 113. https://doi.org/10.1080 /00220670009598749.

Mullis, I. V. S., Martin, M. O., Foy, P., \& Hooper, M. (2017). PIRLS 2016 International Results in Reading. TIMSS \& PIRLS International Study Center: Retrieved from Boston College.

McFarland, J., Hussar, B., de Brey, C., Snyder, T., Wang, X., Wilkinson-Flicker, S., Gebrekristos, S., Zhang, J., Rathbun, A., Barmer, A., Bullock Mann, F., and Hinz, S. (2017). The Condition of Education 2017 (NCES 2017- 144). U.S. Department of Education. Washington, DC: National Center for Education Statistics.

National Reading Panel (U.S.) (2000) 'Teaching children to read: An evidence-based assessment of the scientific research literature on reading and its implications for reading instruction', Washington DC: National Institute of Child Health and Human Development, National Institutes of Health, 4-46.

NGA Center and CCSSO (2010). Common Core State Standards for English language arts \& literacy in history/social studies, science, and technical subjects. Appendix A. Washington, DC: National Governors Association Center for Best Practices Officers.

OECD (2010a), PISA 2009 Results: What Students Know and Can Do - Student Performance in Reading, Mathematics and Science (Volume I). https://doi.org/10.1787/19963777

OECD (2010b), PISA 2009 Results: Overcoming Social Background: Equity in Learning Opportunities and Outcomes (Volume II), PISA, OECD Publishing, Paris, https://doi.org/10.1787/9789264091504-en

Pérez-Granados, D. R., \& Callanan, M. A. (1997). Parents and siblings as early resources for young children's learning in Mexican-descent families. Hispanic Journal of Behavioral Sciences, 19(1), 3-33. https://doi. org/10.1177/07399863970191001. 
Reardon, S. F. (2011). The widening academic achievement gap between the rich and the poor: New evidence and possible explanations. In G. J. Duncan \& R. J. Murnane (Eds.), Whither opportunity? Rising inequality, schools, and children's life chances (pp. 91-116). New York: Russell Sage Foundation.

Resta, P., \& Laferrière, T. (2007). Technology in Support of Collaborative Learning. Educational Psychology Review, 19, 65-83. https://doi.org/10.1007/s10648-007-9042-7.

Rienties, B., Giesbers, B., Tempelaar, D., Lygo-Baker, S., Segers, M., \& Gijselaers, W. (2012). The role of scaffolding and motivation in CSCL. Computers \& Education, 59(3), 893-906. https://doi.org/10.1016/j. compedu.2012.04.010.

Rojas-Drummond, S., Mazón, N., Littleton, K., \& Vélez, M. (2014). Developing reading comprehension through collaborative learning. Journal of Research in Reading, 37(2), 138-158. https://doi.org/10.1111 j.1467-9817.2011.01526.x.

Siemens, G. (2005). Connectivism: A learning theory for the digital age. International Journal of Instructional Technology and Distance Learning, 2, 3-10.

Shanahan, T., Fisher, D., \& Frey, N. (2012). The Challenge of Challenging Text. Educational Leadership., $69(6), 58-62$.

Shanahan T., (2005) The National Reading Panel Report: Practical Advice for Teachers, Learning Point Associates.

Stahl, G., Koschmann, T., \& Suthers, D. (2006). Computer-supported collaborative learning: An historical perspective. In R. K. Sawyer (Ed.), Cambridge Handbook of the Learning Sciences (pp. 409-426). Cambridge: Cambridge University Press.

Stahl, G. (2012). Traversing planes of learning. International Journal of Computer-Supported Collaborative Learning., 7(4), 467-473.

Stevens, R., Slavin, R., \& Farnish, A. (1991). The effects of cooperative learning and direct instruction in reading comprehension strategies on main idea identification. Journal of Educational Psychology, 83(1), 8-16. https://doi.org/10.1037/0022-0663.83.1.8.

Strauss, S., \& Ziv, M. (2012). Teaching is a natural cognitive ability for humans. Mind, Brain and Education, 6(4), 186-196. https://doi.org/10.1111/j.1751-228X.2012.01156.x.

Wanzek, J., Wexler, J., Vaughn, S., \& Ciullo, S. (2010). Reading interventions for struggling readers in upper elementary grades: A synthesis of 20 years of research. Reading and Writing, 23(8), 889-912. https://doi. org/10.1007/s11145-009-9179-5.

Yang, S., Lin, C., Yang, M., Shaon, Y., Chen, W (2011) Computer-supported Collaborative Learning for Elementary School Students on the Effectiveness of Reading Comprehension in T. Hirashima et al. Eds. Proceedings of the 19th International Conference on Computers in Education. Chiang Mai: Asia-Pacific Society for Computers in Education.

Publisher's note Springer Nature remains neutral with regard to jurisdictional claims in published maps and institutional affiliations. 